\title{
Choice Between Composite and Amalgam Restorations According to Dentists and Patients Perception
}

\section{Hanan Nahel H.D.D}

\section{Asaad Mohammed MSc.}

\section{Dr. Raya Al-Naimi}

BDc, MSc, PhD (Assist Prof.)
Department of Conservative Dentistry Al-Noor Specialized Center, Nineveh Health Directorate

Department of Conservative Dentistry Al-Noor Specialized Center, Nineveh Health Directorate

Department of Pedo. Ortho. Preventive Dentistry College of Dentistry, University of Mosul

\begin{abstract}
الخلاصة

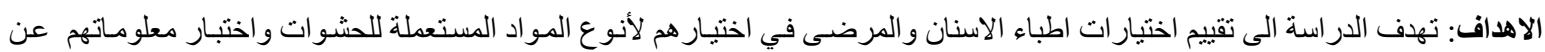

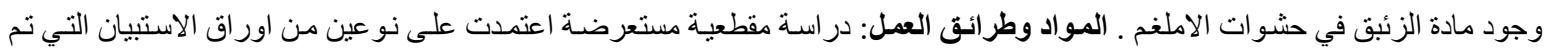

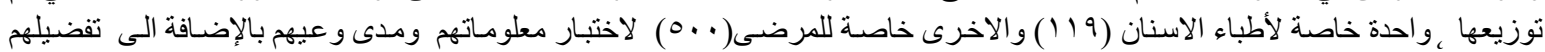

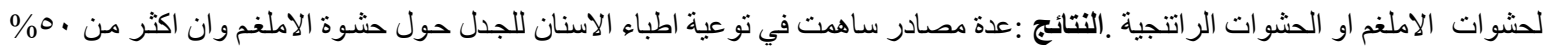

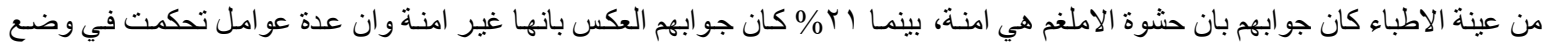

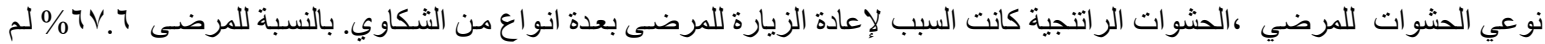

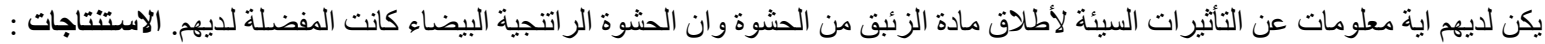

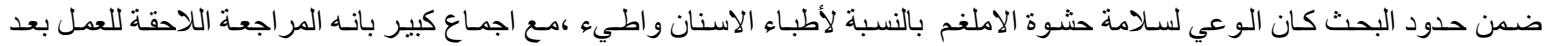

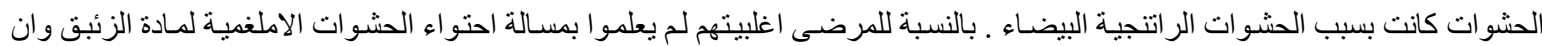

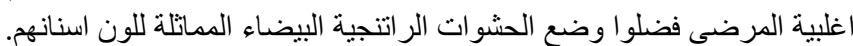

\begin{abstract}
Aims : The aim of the current study was to evaluate dentists and patients choices of type of restorative materials applied in fillings and their knowledge about the mercury content in amalgam restorations. Matrials and Methods: a cross sectional descriptive study based on two types of questionnaire, one for the dentists(119) and the other specific for the patients (500) were distributed to determine the knowledge and awareness, preference of amalgam and composite restorations. Results: showed that the awareness of the dentists about the amalgam controversy came from different sources, half of the dentists sample stated amalgam restorations were safe, were as $21 \%$ of the sample stated it unsafe. Placement of the selected restoration(either type) was influenced by different factors, recall appointments of patients complaining from several complaint was mostly from composite, $67.6 \%$ of patients didn't have any knowledge about harmful effect of mercury release from amalgam with the majority of the patients stating that they preferred composite or a tooth colored restoration. Conclusion: within the limitations of this study awareness of safety of dental amalgam among the dentists was low, with a large agreement that postoperative complications were mainly due to composite restorations. For the patients, the majority of them did not know anything about issues related to the mercury content of the amalgam and the majority of them favored the placement of composite restoration similar to the color of their teeth.
\end{abstract}

Key words: Amalgam, Composite, Choice, Dentist, Patients, Mercury

Nahel H., Mohammed A., Al-Naimi R. Choice Between Composite and Amalgam Restorations According to Dentists and Patients Perception. Al-Rafidain Dent J. 2020 ;20 (1): 1-17.

DOI: $10.33899 /$ rden. 2020.126468.1015

Received: 31/12/2019

Sent to Referees: 2/1/2020

Accepted for Publication: 23/2/2020

Vol. 20, No1, 2020 


\section{INTRODUCTION}

Worldwide and for more than 150 years, amalgam has been known for more than being a dental restorative material, it has proved to be a valuable and dependable filling materials which is relatively cheap and tolerant to the oral environment with minimum problems for millions of patients around the world ${ }^{(1,2) .}$ The war on amalgam is not new, it began in 1843 as the American Society of Dental Surgeons (ASDS) declared use of amalgam to be malpractice because of the fear of harmful effect of mercury to the dentist and patient in addition to its disposal in the environment ${ }^{(3,4) \text {, }}$ so that some countries banned the use of amalgam for all the populations (Norway, Sweden and Germany) (5,6), while other countries including Finland, Denmark and the Netherlands have phased down dental amalgam usage to $1-5 \%$ of restorations banning it in the vulnerable population like small children and pregnant ladies ${ }^{(7)}$. In 2013 the Minamata Convention on Mercury, had the objective of protecting human health and environment from anthropogenic emissions and releases of mercury, the convention stressed parties and countries to phase down amalgam by reducing the mining, use and trade in mercury worldwide and ultimate elimination in the production and use of mercury containing products ${ }^{(8)}$.

Alternatives to amalgam are composite restorations that have been improved in their formulations in order to withstand and tolerate excessive stress and wear in addition to glass ionomer restorations and compomer ${ }^{(9,10,11)}$.

The aim of the current study was to assess the source of awareness of dental personnel's working in Mosul city to the use of dental amalgam, opinion and safety of amalgam restorations, use of composite, and other related factors for replacement of amalgam with composite and causes of recall appointments, questionnaires for patients aimed also to determine the level of awareness about the possible harmful effect of mercury in amalgam fillings on their health, their acceptance of amalgam fillings, their preference in type of restoration(amalgam or composite), and knowledge about the stronger restoration.

\section{MATERIALS AND METHODS}

The protocol designed for this study, was approved by the College of Dentistry, University of Mosul, and Nineveh Health Directorate training center and human development. Two types of questionnaires, one for the dental personnel and the other specific for the patients were structured by the authors from relevant publications ${ }^{(12,13)}$ that was modified and then distributed at the College of Dentistry, University of Mosul and at Al Noor Specialized dental health center, containing mostly close ended questions. The first specific for the dentist that consisted of sociodemographic and practice characteristics such 
as gender, years of service, specialty, sources of awareness about amalgam controversy, opinion about amalgam restorations, the treatment needs of patients, uses of amalgam and its

1. Demographic data and professional capability:

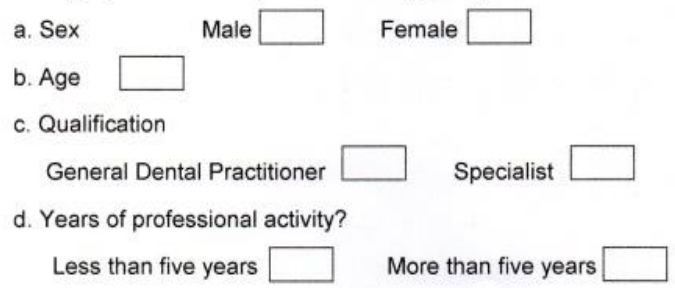

2. Source of awareness from amalgam controversy(not favoured):

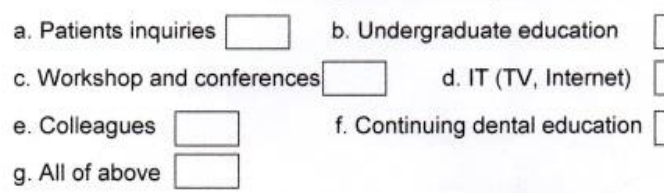

3. Opinion about amalgam safety:

a. Safe for the practitioner and patient

b. Unsafe for the practitioner and patient

c. Uncertain

4.Placement and removal of amalgam and use of its alternatives:

a. According to which criteria you will select amalgam as a material of choice?
1. Sex
3. Patient attitude
2. Degree of education
4. Affordability

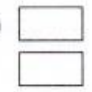

b. What is your opinion about dental amalgam as a restorative material?

1. Longevity and superior mechanical properties

2. Applicable and less technique sensitive alternative, the properties and usefulness of both types of restoration materials both questionnaires can be seen in Figures (1) and (2).

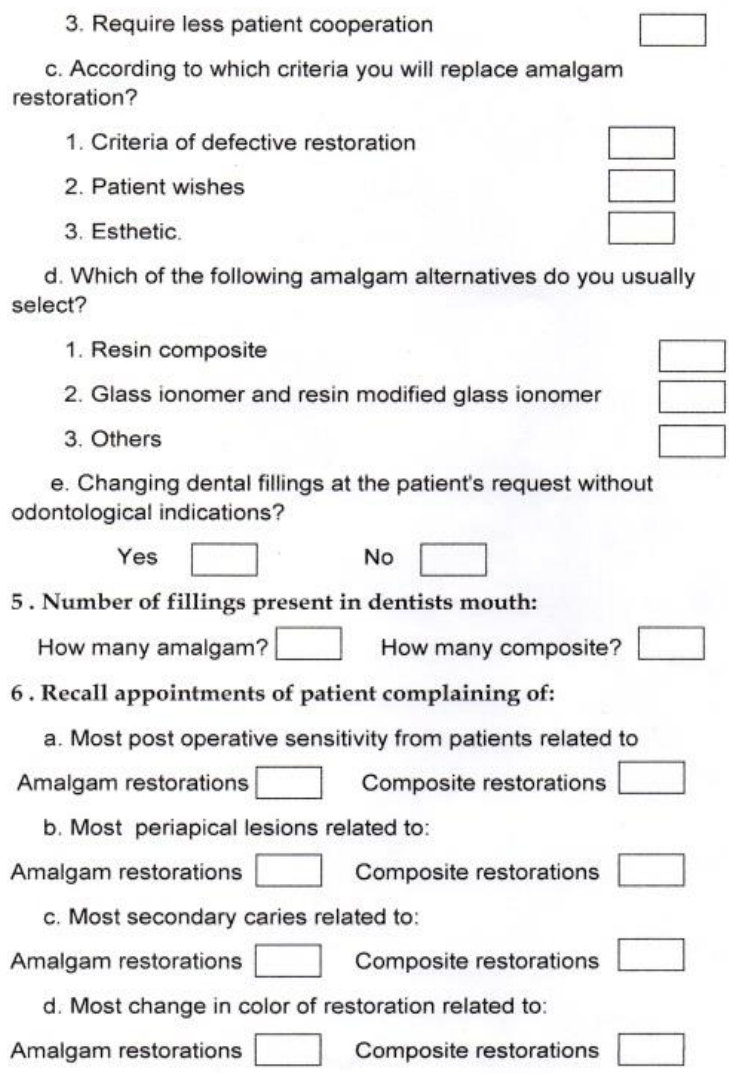

Figure (1): Questionnaire for Dentists 


\section{Questions for patients}

1-Demographic data:

a. Age

b. Sex

male

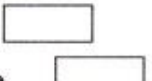

c. Educational level of the patient

2-Awareness of patients with dental fillings about the harmful effect of mercury in dental amalgam :

a. Knowledge about dental fillings?

b. Have you heard about the adverse reaction of dental amalgam?

c. Harmful effect of mercury in dental amalgam?

3-Acceptance of amalgam filling with or without prior information about its mercury content:

a. Filling their cavities with dental amalgam?

b. Filling their cavities with amalgam alternatives?

4-Do you prefer amalgam?

Yes $\square$ No

5-Do you prefer composite (white colored restoration)?

$$
\text { Yes }
$$

No

6-Why do you prefer?

a. Esthetic

b. Stronger and longetivity

c. Cost

7-Knowledge about stronger filling ( what ever type) obtained from:

a. Media ( TV, Internet, Radio)

b. Heard from other person

c. Price of restoration (composite more expensive)

d. None of all above.

Figure (2): Questionnaire for patients

Patient's awareness and acceptance was assessed by means of structured questionnaire prepared based on commonly asked questions from routine daily practice. Knowledge of mercury content in amalgam restorations, also their acceptance with filling their cavities by 
dental amalgam with or without prior information about its mercury content or use of other alternatives, causes of their preference and knowledge about the strength and durability of the type of restoration they preferred. This part was completed via dentists asking the questions to the patients that participated in this survey.

\section{Statistical Analysis:}

Statistical analysis was performed using SPSS programme version 16, and frequencies and percentages were calculated.

\section{RESULTS}

Table (1) demonstrates the demographic variables of the 119 dental personnel participating in the study, $51.26 \%$ were males while $48.74 \%$ were females, majority of the sample $63.87 \%$ had more than 5 years of service, with $57.14 \%$ being general dental practitioners while the rest were specialists in different fields of Dentistry.

Table (1): Demographic Variables of the Dental Personnel

\begin{tabular}{ccc}
\hline Gender & No. & \% \\
\hline Male & 61 & 51.26 \\
Female & 58 & 48.74 \\
Years of Service & & \\
Less than or equal to 5 years & 43 & 36.13 \\
More than 5 years & 76 & 63.87 \\
Specialty & & \\
General Dental Practitioners & 68 & 57.14 \\
Specialist & 51 & 42.86 \\
\hline
\end{tabular}

Table (2) shows the source of awareness of the dentists about the amalgam controversy, and that $52.9 \%$ of the dentists knew about the amalgam controversy from several sources. 
Table (2): Source of Awareness of the Dentists About the Amalgam Controversy

\begin{tabular}{ccc}
\hline Awareness Source & Frequency & Percentage (\%) \\
\hline Patients Inquiries & 10 & 8.4 \\
Undergraduate Education & 8 & 6.7 \\
Workshops & 2 & 1.7 \\
T.V \& Internet & 25 & 21 \\
Colleagues & 3 & 2.5 \\
Continuing Education & 8 & 6.7 \\
All of the Above & 63 & 52.9 \\
\hline
\end{tabular}

Table (3) illustrates opinion of the restorations were safe, $21 \%$ stated amalgam as dentists about the safety of dental restorations, unsafe, while $28.6 \%$ were uncertain about its $50.4 \%$ of the dentists stated amalgam safety.

Table (3): Dentists Opinion About the Safety of Amalgam Restorations

\begin{tabular}{ccc}
\hline Opinion About Amalgam & Frequency & Percentage (\%) \\
\hline Safe & 60 & 50.4 \\
Unsafe & 25 & 21 \\
Uncertain & 34 & 28.6 \\
\hline
\end{tabular}

It can be shown in Table (4) that dentists placed amalgam, composite and other tooth colored restorations according to patients attitude with a percentage of 48.7 , while $42 \%$ of the dentist placed the restorations that the patient could afford, while $7.6 \%$ of the dentists placed restorations according to educational level of their patients (i.e. placed tooth colored restorations to higher educational level). 
Dentists and Patients Choice Between Amalgam and Composite Restorations

Table (4): Factors Influencing Placement of Amalgam Restorations or Alternatives

\begin{tabular}{ccc}
\hline Placement of Amalgam \& Alternatives & Frequency & Percentage (\%) \\
\hline Gender & 2 & 1.7 \\
Degree of education & 9 & 7.6 \\
Patients Attitude & 58 & 48.7 \\
Affordability & 50 & 42 \\
\hline
\end{tabular}

Table (5) demonstrates dentists opinion about amalgam as a restorative material, $49.6 \%$ of dentists stated that amalgam restorations had a more longevity in the mouth, $22.7 \%$ stated that its application was less technique sensitive, while $4.2 \%$ of dentists used amalgam because it required less patient cooperation, $23.5 \%$ opinion was a combination of all the previous factors.

Table (5): Opinion About Amalgam as a Restorative

\begin{tabular}{ccc}
\hline Opinion About Amalgam Restorations & Frequency & Percentage(\%) \\
\hline Longevity & 59 & 49.6 \\
Less Technique Sensitive & 27 & 22.7 \\
Require less Patient Cooperation & 5 & 4.2 \\
All of the above & 28 & 23.5 \\
\hline
\end{tabular}

The dentists opinion on when to replace amalgam restorations can be seen in Table (6),42.9\% stated that they replaced amalgam when it had a defect, $38.6 \%$ stated that they replaced amalgam to improve the esthetics while $18.5 \%$ of dentists replaced amalgam depending on the patient's wishes. 
Table (6): When to Replace Amalgam with Composite or Tooth Colored Restorations

\begin{tabular}{ccc}
\hline Placement of Amalgam \& According to & Frequency & Percentage (\%) \\
\hline Defective Restoration & 51 & 42.9 \\
Patient Wishes & 22 & 18.5 \\
Esthetic & 46 & 38.6 \\
\hline
\end{tabular}

Figure (3) displays types of amalgam modified glass ionomers, while $2.5 \%$ used alternatives the dentists select, majority choice other means like ceramics as indirect was composite resins $86.6 \%$, only $10.9 \%$ stated restoration in addition to compomers and they preferred glass ionomers and resin giomer

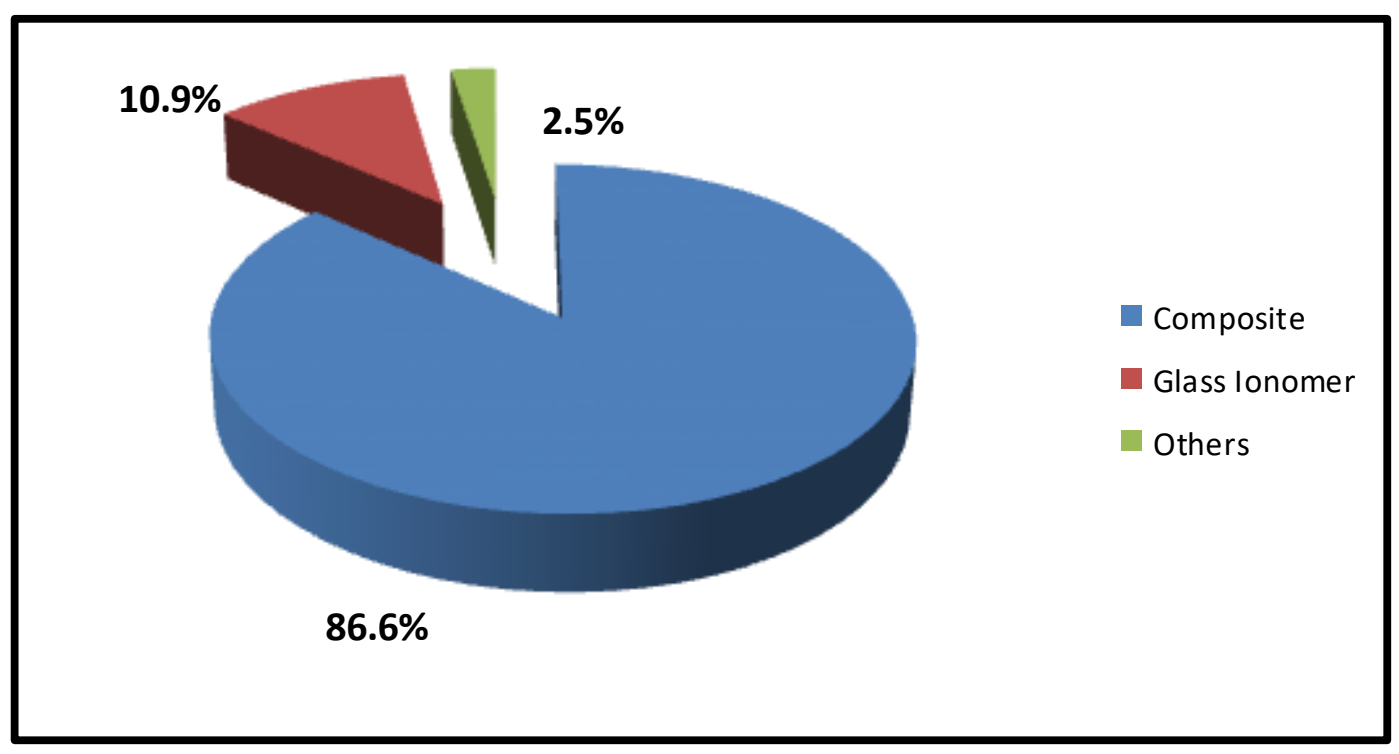

Figure (3): Types of Amalgam Alternatives the Dentists Select

When the dentists were asked if they would change amalgam restorations to composite without an odontological indication, $31.1 \%$ agreed to change while $68.9 \%$ stated that they couldn't change amalgam restoration if the restoration was faultless. Figure demonstrate types of restorations present in the dentists mouth which was mostly both types of restorations (i.e. amalgam and composite) with a percentage of $68.1 \%$. 


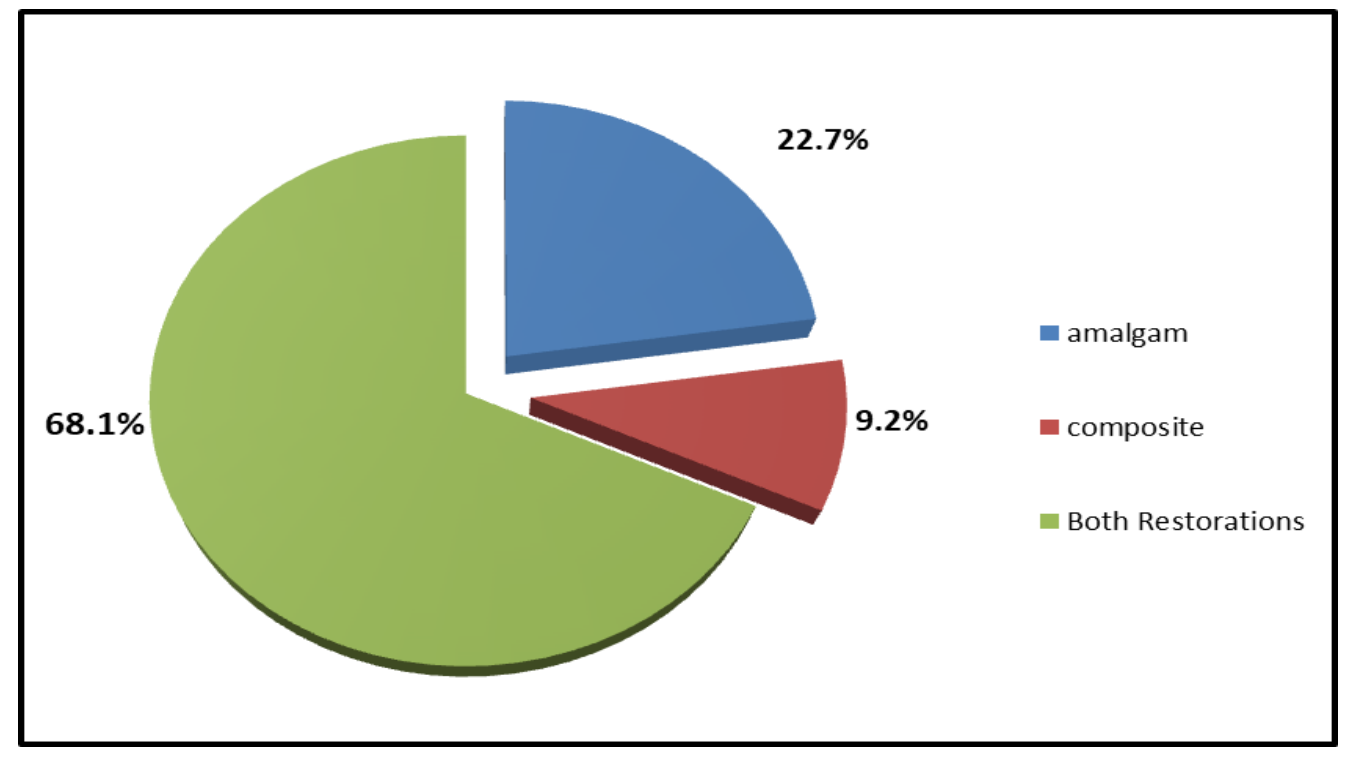

Figure (4): Types of Restorations Present in the Dentists Mouth

Table (7) depicts the recall appointments of patients complaining from post-operative complications including sensitivity, periapical lesions, secondary caries and changes of color of restorations were mostly from the composite restorations with a range (76.5-90.8)\% while amalgam restorations exhibited complications with a range between $(9.2-23.5) \%$.

Table (7): Recall Appointments of Patients Complaining From

\begin{tabular}{ccccc}
\hline Complaint & Frequency & $\begin{array}{c}\text { Amalgam } \\
\text { Percentage } \\
(\mathbf{\%})\end{array}$ & Frequency & $\begin{array}{c}\text { Percentage } \\
(\%)\end{array}$ \\
\hline $\begin{array}{c}\text { Post-Operative } \\
\text { Sensitivity } \\
\text { Periapical Lesions }\end{array}$ & 22 & 18.5 & 97 & 81.5 \\
$\begin{array}{c}\text { Secondary Caries } \\
\begin{array}{c}\text { Change in Color of } \\
\text { Restorations }\end{array}\end{array}$ & 11 & 9.2 & 108 & 90.8 \\
\hline
\end{tabular}


Distribution of the sample of patients by contributed $48.2 \%$ with a total of (241) as age is shown in Table (8), the sample was shown in Table (9). Table (10) displays composed of 500 individuals, distributed in to 4 educational level of the patients, $30.2 \%$ of the age groups, majority of the sample was in the sample were Illiterate or had finished primary age group equal or less than 30 years old with school, $30 \%$ had completed secondary school a percentage of $51.4 \%$. Females contributed ,while higher levels of education were seen in $51.8 \%$ of the sample (total 259), while males $36.8 \%$ of the sample.

Table (8): Distribution of the Patients by Age

\begin{tabular}{ccl}
\hline Age Groups & Frequency & Percentage (\%) \\
\hline$\leq 20$ & 73 & 14.6 \\
$\leq 30$ & 257 & 51.4 \\
$\leq 40$ & 107 & 21.4 \\
$\leq 50$ & 63 & 12.6 \\
\hline
\end{tabular}

Table (9): Distribution of the Sample by Gender

\begin{tabular}{ccc}
\hline Gender & Frequency & Percentage (\%) \\
\hline Male & 241 & 48.2 \\
Female & 259 & 51.8 \\
\hline
\end{tabular}

Table (10): Educational Level of Patients

\begin{tabular}{ccl}
\hline Educational Level of Patients & Frequency & Percentage (\%) \\
\hline Illiterate or Primary School & 166 & 33.2 \\
Secondary School & 150 & 30 \\
Bachelor's Degree or Higher & 184 & 36.8 \\
\hline
\end{tabular}


Table (11) displays the awareness of the or amalgam adverse effects, while $67.6 \%$ patients about dental amalgam, 32.4\% had hadn't heard about the adverse effect of heard about the harmful effect of the mercury mercury in the restoration.

Table (11): Awareness of Patients About Harmful Effect of Mercury in Amalgam Restorations

\begin{tabular}{lcc}
\hline \multicolumn{1}{c}{ Awareness } & Frequency & Percentage(\%) \\
\hline $\begin{array}{l}\text { Heard about harmful effect of mercury in } \\
\text { the filling or adverse reaction of amalgam }\end{array}$ & 162 & 32.4 \\
$\begin{array}{l}\text { Did not know anything about harmful effect } \\
\text { of mercury release from amalgam }\end{array}$ & 338 & 67.6 \\
\hline
\end{tabular}

For the acceptance of the amalgam restoration, when the patients were asked about the type of restoration they preferred regardless of the dentists opinion that is seen in Table (12), only $30 \%$ (150) stated they preferred amalgam restorations, while $70 \%$ favored composite restorations. Table (13) shows the reasons of the patients choice of either type of restoration, 70\% (350) stated that they were concerned with the esthetic, 27\% (135) were concerned about the strength and longevity of life time of restoration, while only $3 \%$ (15) stated that the lower cost of amalgam restorations influenced their choice.

Table (12): Type of Restorations Preference by Patients

\begin{tabular}{ccc}
\hline Restoration Preference & Frequency & Percentage(\%) \\
\hline Amalgam Restorations & 150 & 30 \\
Composite restorations & 350 & 70 \\
\hline
\end{tabular}

Table (13): Cause of the Patients Choice of the Type of Restoration Whether Amalgam or Composite

\begin{tabular}{ccc}
\hline Causes of Preference & Frequency & Percentage (\%) \\
\hline Esthetic & 350 & 70 \\
$\begin{array}{c}\text { Stronger\& longevity of life } \\
\text { time of restoration }\end{array}$ & 135 & 27 \\
Cost of Restoration & 15 & 3 \\
\hline
\end{tabular}


Figure (5) displays the patients source of knowledge of the stronger restoration that they preferred, 3\% (15) stated that cost influenced their choice of the type of restoration , $27.6 \%$ (138) had heard from the media, $18.2 \%$ (91) had heard from other persons, while 51.2\% stated that the reason was non of the above like the available type of restoration in the health center or the dentist choice of the type of restoration.

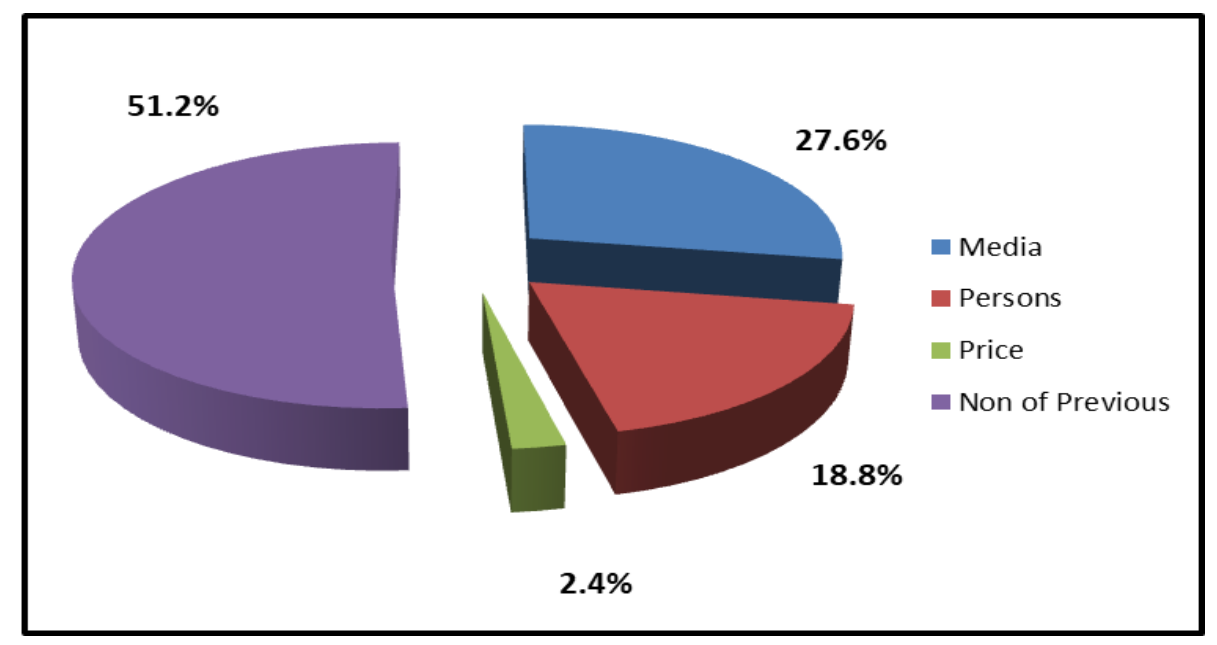

Figure (5): Patients Source of Knowledge of the Better Restoration

\section{DISCUSSION}

One of the strategies to combat and treat dental caries is by applying restorations. If decay is left untreated, dental caries leads to discomfort and sometimes to sever pain, eventually requiring the removal of affected teeth. Dental restorations failure is a major problem in dental practice and the replacement of restorations constitutes the majority of the operative work. Dental amalgam is a widely employed restorative material that contains approximately $50 \%$ mercury ${ }^{(14)}$. The current cross sectional study aimed at evaluating dentists and patients perception and preferences to the major types of restorations known in dentistry and that are mostly used.

Looking at the demographic variables of the cluster sample of dentists that participated in this survey showed that male dentists were slightly larger than female dentists, with the majority having served for more than 5 years and were mostly general dental practitioners. When dentist were asked source of awareness of the dentists about the amalgam controversy, Majority (52.9\% )stated that a combination of patients inquiries, undergraduate education, 
workshops, T.V and Internet, colleagues and courses of continuing education contributed to their knowledge of the amalgam controversy. T.V. in addition to the internet contributed to a large proportion of their knowledge (i.e. 21\%), advances in information technology have changed our life-style and the use of the internet can be considered as a part of the dentists daily activity and this technology has become as ordinary as the telephone or television ${ }^{(15)}$ it is also cost-effective as it can be accessed from anywhere and at any time. The information on the internet is usually updated, which helps in updating the recent knowledge and motivate dentists to undertake research activity on any particular field ${ }^{(16)}$.When the dentists were asked about the safety of the amalgam restorations $50.4 \%$ of the sample replied that it is safe, this is much more than that reported in a previous study that reported a $10.82 \%$ of the dentists opinion that amalgam is safe ${ }^{(13)}$, according to the ADA opinion about amalgam is that it is the safest and most affordable and durable dental materials for specific treatment needs ${ }^{(17)}$, this includes the option to use dental amalgam, which the scientific community has extensively reviewed and affirmed to be a safe and effective restorative material, the results of two independent clinical trials designed to examine the effects of mercury release from amalgam on the central and peripheral nervous systems and kidney function noted that "there were no statistically significant differences in adverse neuropsychological or renal effects observed over the 5-year period in children whose caries was restored using dental amalgam or composite materials" ${ }^{(18,19)}$ and although some people express concern about mercury vapor released from dental amalgam the quantity released is well below the limits set by the US Environmental Protection Agency and the World Health Organization ${ }^{(20)}$.Yet a large proportion of dentists $28.6 \%$ were uncertain about the safety of amalgam restorations, this figure is more than that reported in another study ${ }^{(12)}$.

When the dentists were asked about reason for filling with the type of restoration placed whether amalgam or composite , $48.7 \%$ replied that the attitude and desire of the patients played a very important role in the dentists choice of the type of restoration, according to Christensen (2002) ${ }^{(21)}$ dentists will continue to experience an increased demand for their services, largely on the strength of patients' desires for having a better-looking smile so patients chose tooth colored restorations, while large proportion $42 \%$ of dentists placed either type of restoration according to the financial state of patients as composite restorations are more expensive. Half of the dentists opinion about the amalgam restorations that it is more durable and last longer in patients mouth compared to tooth colored restorations, this is in agreement with other studies ${ }^{(19,22,23)} .22 .7 \%$ of the sample 
said that the amalgam restorations were less technique sensitive as the isolation of the operating area for an amalgam restoration is less critical than for composite, this is in agreement with other studies ${ }^{(23,24,25)}$.

When the dentist were asked when to replace amalgam restorations, the majority 42.9 $\%$ stated when there is a defective restoration, while $38.6 \%$ stated that they would replace amalgam according to their judgment for esthetic purposes, and only $18.5 \%$ agreed to replace amalgam according to patients wishes. The current study showed that that the majority of dentists agreed that the recall appointments of patients complaining from post-operative sensitivity, periapical lesions, secondary caries and changes in color of restorations were mostly attributed to the tooth colored restorations (mostly composite) with a range of (76.5-90.8) \% for all types of complications, while amalgam exhibited the least percentage of these complications with a range between (9.2- 23.5$) \%$, this is in agreement with Port (2012) ${ }^{(26)}$, Post-operative sensitivity in resin composite restorations is a common complication that causes discomfort to the patient and inconvenience to the professional, because it has many different causes.

For the patient sample, the largest proportion of the sample was in the age group equal to or less than 30 years and the primary aim of applying restorations was primary caries, with females attending for treatment more than males which is attributed to the reason the youth and females utilize dental services more than males (27) and are more considerable about their appearance.

An interesting finding was that the majority of the sample of patients $67.6 \%$ did not know anything about issues related to the mercury content of the amalgam restorations and the harmful effect of mercury in general, this figure is in agreement with another study in North of Iraq ${ }^{(13)}$, and a study in Turkey ${ }^{(28)}$. But when the patients were asked about the type of restorations they preferred $70 \%$ stated that they wanted tooth colored restorations or as they said white fillings in comparison with black ones, In today's society, people want to look their best, since physical appearance and esthetics matters the most and this plays an important role in the individuals self-esteem and success so the quest for an improved appearance even intra orally has become synonymous with cosmetic intervention and trying to feel beautiful through various health professionals in the dental field, of the $30 \%$ that chose amalgam $27 \%$ of the sample stated that the cause of their choice of restoration was that they were looking for the stronger\& longevity of life time of restoration, there is no doubt that amalgam shows superiority when compared to that of composites, this is in agreement with other studies ${ }^{(25,29,30,31)}$ and in no doubt can it be replaced for the time being. 
A small proportion stated that cost was a factor to be considered when putting a dental restoration, Iraq is a developing country that has undergone many economical and political issues after the year 2003 that has thrown its shadows on the Iraqis particularly the Mosuli community that has been affected in terms of availability and the cost of materials which varies between countries. Composites restorations are more expensive than amalgam and, as a result, the use of dental amalgam is still common, other higher-income developed countries have introduced a ban on use of dental amalgam as a restorative material, taking into considerations the higher availability and accessibility of alternative tooth-colored dental materials especially composite, in addition to introducing a comprehensive preventive dental care programme for every individual. The use of amalgam has been decreasing not because of public perception on mercury toxicity or environmental issues but due to the increased demand for esthetic restoratives. Amalgam is superior over composite as it fulfills almost all criterions except esthetics. Amalgam is more durable than composite resins, the application of silver amalgam shall not decline with in the coming years in Iraq particularly in Mosul city.

\section{CONCLUSIONS}

Within the limitation of this study (limited number of dentists and patients) awareness about the safety of amalgam restorations among the dentists was low, with most of the dentist agreed that amalgam is easy to use, has lower cost as compared to composite and produces less postoperative problems. Patients knowledge about the mercury content in amalgam was very low, with the majority of the sample requesting a composite or tooth like restoration. Amalgam is still popular among patients and dentists in Mosul.

\section{REFERENCES}

1. Berry TG, Summit JB, Chung AK, Osborne JW. Amalgam at the new millennium. $J A m$ Dent Assoc. 1998;129:1547-56.

2-Rasines Alcaraz MG, Veitz-Keenan A, Sahrmann P, Schmidlin PR, Davis D, IheozorEjiofor Z. Direct composite resin fillings versus amalgam fillings for permanent or adult posterior teeth. Cochrane Database Syst Rev. $2014 ; 31(3): 1-47$

3-Molin C. Amalgam--fact and fiction. Scand J Dent Res. 1992;100:66-73.

4-Khalaf ME , Alomari QD, Omar R. Factors relating to usage patterns of amalgam and resin composite for posterior restorations - a prospective analysis. J Dent. 2014 ; 42(7): 785-792.

5- Norwegian ministry of the environment. Amendments of regulations of 1 June 2004 No. 922 relating to restrictions on the use of chemicals and other products hazardous to health and environment (product regulations). 2004.www.regjeringen.no/en/dep/md/search.ht 
$\mathrm{ml}$ ?querystring $=$ hazardous + chemicals $\& \mathrm{id}=870$

62. Accessed 20 september Jun 2019.

6-Eley BM. Have Germany and Sweden banned the use of amalgam? Dent Update. 1996;23:313-4,28.

7-Lessons from Countries Phasing Down Dental Amalgam Use. United Nations Environment Programme, 2016. UNEP Chemicals and Waste Branch,

Geneva,

Switzerland.https://wedocs.unep.org/bitstream/ handle/20.500.11822/11624/Dental.Amalgam.

8-Mercury convention. Minamata convention on mercury.2013.http://www.mercuryconvention.o rg/Portals/11/documents/Booklets/Minamata\% 20Convention\%20on\%20Mercury_booklet_En glish.pdf. Accessed 22 Sept. 2019.

9- Sachdeva S, Kapoor P, Tamrakar AK, Noor R . Nano-Composite Dental Resins: An Overview. Annals of Dental Specialty. 2015 .3( 2.):52-55.

10-Lynch CD, D. Farnell DJJ, Stanton H, Chestnut IG, Brunton PA \&Wilson\& NH F . No more amalgams: Use of amalgam and amalgam alternative materials in primary dental care. Brit Dent J. 2018 . 225: 171-176.

11- Kevin J ,Donly, Issa S Sasa. Dental materials in Pediatric Dentistry Infancy through Adolescence. J. Nowak, Christensen JR, Mabry TR , Townsend JA and Wells MH $6^{\text {th }}$ Ed. Philadelphia, Elsevier.2019. pp293-303.
12- Udoye C \& E Aguwa E. Amalgam Safety and Dentists' Attitude: A Survey Among a Subpopulation of Nigerian Dentists. $J$ Oper Dent. 2008;33(4): 467-471

13- Faraj BM, Mohammad HM, and Mohammad KM. The Changes in Dentists' Perception and Patient's Acceptance on Amalgam Restoration in Kurdistan-Iraq: A Questionnaire-based Cross-Sectional Study. J Clin Diagn Res. 2015; 9(4): ZC22-ZC25.

14-WHO (2011) - Future Use of Materials for Dental Restoration, World Health Organization,Geneva,2011; http://www.who.int/ oral_health/publications/

dental_material_2011.pdf

15- Unnikrishnan B, Kulshrestha V, Saraf A, Agrahari AC, Prakash S, Samantaray L, et al. Pattern of computer and internet use among medical students in Costal South India. S East Asian J Med Educ. 2008;2:18-25

16- Jali PK, Singh S, Babaji P,1 Chaurasia VR, Somasundaram P, and Lau H. Knowledge and attitude about computer and internet usage among dental students in Western Rajasthan. India. J Int Soc Prev Community Dent. 2014; 4(1): 29-34.

17- Mark AM. Amalgam fillings: safe, strong, and affordable. J Am Dent Assoc.. 2019; 150( 10) : 894 .

18- Bellinger DC, Trachtenberg F, Barregard L, et al. Neuropsychological and renal effects of 
dental amalgam in children: a randomized clinical trial. $J \quad A m$ Dent Assoc.2006;295(15):1775-83.

19- Bellinger DC, Daniel D, Trachtenberg F, Tavares M, McKinlay S. Dental amalgam restorations and children's neuropsychological function: the New England Children's Amalgam Trial. Environ Health Perspect $.2007 ; 115(3): 443-6$.

20-World Health Organization . Exposure to Mercury: A Major Public Health Concern. Geneva, Switzerland. 2007.Available at https://www.who.int/ipcs/features/mercury.pdf

21- Christensen GJ . Are prosthodontics a vital part of dentistry? J Am Dent Assoc.2002;133: 647-648.

22- Shenoy A. Is it the end of the road for dental amalgam? A critical review. J Conserv Dent. 2008;11(3): 99-107.

23- Patki B. Direct permanent RestorativesAmalgam vs Composite. J Evolut Medic and Dent Scie. 2013; 2,(46),: 8912-8918.

24-Roberson T, Heymann H, Ritter A, Pereira P. Classes I, II and VI Direct Composite and Other Totth-Colored Restorations. In:Roberson T, Heymann H, Swift E. Sturdevant's Art\& Science of Operative Dentistry. $4^{\mathrm{a}}$ ed. Missouri: Mosby; 2002; 539-567.

25- Soncini JA, Maserejian NN, Trachtenberg F, Tavares M, Hayes C.The longevity of amalgam versus compomer/compositerestorations in posterior primary and permanent teeth: Findings from the New England Children's Amalgam Trial. $J$ Am Dent Assoc. 2007;138:763-772.

26- Porto, I.C.C.M. Post-operative sensitivity in direct resin composite restorations: Clinical practice guidelines. IJRD .2012;1:1-12.

27- Obeidat SF, Alsa'di AGh \& Taani DS. Factors influencing dental care access in Jordanian adults. BMC Oral Health. 2014; 14:127:1-7.

28- Emrullah B,Bayram I,Hakan C,zehra SY,Candan AH\& zekiA. What do patients think about mercury in dental amalgam? Findings from Southeast part of Turkey. Adv Dent \& Oral Health. 2016; 2(4) :1-5.

29- Kim KL, Namgung $\mathrm{C}$ and Cho BH. The effect of clinical performance on the survival estimates of direct restorations. Restor Dent Endod. 2013; 38(1):11-20.

30- Moraschini V, Fai CK, Alto RM, Dos Santos GO. Amalgam and resin composite longevity of posterior restorations: A systematic review and meta-analysis. J Dent. 2015;43(9):1043-1050.

31-Uttarwar V, Gunwa M, Sonarkar S, Pradhan M, Mokhade V, Kokane V. Clinical Longevity of Dental Amalgam V/S Resins Based Composites - A Literature Review. J Dent and Med Scie.2019;18(5):62-64. 